\title{
Analyzing the Impact of Large Dams on Seismicity Patterns around Their Locations
}

\author{
Mina Parvizishad ${ }^{1}$, Simin Naseri $^{1}$, Ramin $_{\text {Nabizadeh }}{ }^{1}$, Abdollah \\ Sohrabi Bidar ${ }^{2}$, Amir Hossein Mahvi*1, Fatemeh Goodarzi ${ }^{1}$ \\ ${ }^{1}$ School of Public Health, Tehran University of Medical Sciences, Tehran, Iran, ${ }^{2}$ Department of Geology, \\ College of Science, University of Tehran, Tehran, Iran, ${ }^{*}$ Corresponding author: mahviami@tums.ac.ir
}

(Received March 15, 2021; revised July 03, 2021)

\begin{abstract}
Dam construction is one of the most popular solutions for managing water resources. In recent years, changes in patterns of regional seismicity associated with large impoundment dams have raised concerns among environmentalists. In this study, five large dams located in Iran were studied from this perspective. The Gutenberg-Richter, linear regression and T-test were used to examine the seismic changes in the radius of $100 \mathrm{~km}$ of each of the dams during a twenty-five-year period before and after the construction of the dams. The results revealed that the seismicity level and relative density of large and small earthquakes in three of these dams have increased after dam construction. A significant difference between the magnitude of earthquakes, as well as the number of earthquakes before and after the construction of dams in the region, was recognized. However, the results of the T-test statistical analysis indicated that the mean depth of the earthquakes and their distance from the dams before and after construction have not changed significantly. Overall, these results indicated that the construction of large impoundment dams has been associated with some changes in patterns of regional seismicity. The findings would guide researchers to further investigate the type of impacts that dam construction may have on seismicity patterns.
\end{abstract}

Key words: dam construction, impoundment, seismicity pattern, earthquake

\section{Introduction}

A seismic area describes a zone with a high level of concentration in earthquakes. Iran is one of the most seismically active countries that experienced sixteen major earthquakes with a magnitude of greater than 5.7 on the Richter scale from 1900 to 2014, which led to the death of over 100,000 people (Wald 2015). Apart from natural earthquakes that commonly occur, many induced earthquakes have been identified to be associated with artificial origins related to human activities (Tatar et al 2011) such

(C) 2021 Institute of Hydro-Engineering of the Polish Academy of Sciences. This is an open access article licensed under the Creative Commons Attribution-NonCommercial-NoDerivs License (http://creativecommons.org/licenses/by-nc-nd/3.0/). 
as drilling for natural gas recovery (Frohlich et al 2010), mining (Kusznir et al 1980), gas and fluid injection or extraction (Ohtake 1974, Ellsworth 2013), impounding dams (Simpson 1976, Adnan and Harith 2017). It is argued that such human activities are partly associated with induced earthquakes. Some of these earthquakes as natural earthquakes have caused deaths and property damages with a permanent influence on seismicity patterns. Dam construction has been in place for a long time for better water resources management. However, it is argued that the construction and operation of dams can lead to induced earthquakes due to reasons such as the creation of large new reservoirs (Manouchehri and Mahmoodian 2002). Regarding the construction of dams (about 152 dams were built and operated in Iran since 2014) and the potential seismicity, Iran is a suitable country for undertaking a study on the relationship between dam construction and seismicity patterns (Foltz 2002).

A number of studies have been undertaken recently to study the causes of induced earthquakes and their origins. In some studies, it has been found that the seismicity of the area around the dam was declined after its inauguration (Ibenbrahim et al 1989). This represents the role of dams in changing geological conditions and tectonic state characteristics during a complex phenomenon (Castle et al 1980). Rothe noted that the water level in comparison with the volume of water behind the dams has an important role in seismicity changes (Rothé 2013). On the other hand, many studies have shown that seasonal increases in the water level of the dam's reservoir have been associated with an increase in seismicity (Gupta et al 1972, Gupta 1985, Pavan Kumar et al 2012).

Simpson and Negmatullaev (1981) applied the Gutenberg-Richter method and found that changes in the seismicity parameters around the dam Nurek are obvious. It was also found that earthquakes that immediately occur after dam operation, usually are low in magnitude, occurring near the dam site (Simpson and Negmatullaev 1981b). In their study, an increasing number of earthquakes has been reported after extensive the inauguration of the dam. As evidence, the long-term monitoring of the seismicity of the region for about 20 years before the construction of the dam revealed unusual seismic reactions around the location of the dam (Simpson and Negmatullaev 1981). The details of the monitoring seismicity after dam operation showed that there is a close relationship between the rates of seismicity with small changes in water level in the reservoir (Gupta et al 1972, McGarr et al 2002).

The types of seismic response to dam impoundment can be categorized into (1) quick response, (2) delayed response, and (3) continued response (Gupta 2002). Most earthquakes that occur immediately after dam impoundments have distances less than $10 \mathrm{~km}$ and occur near the dam location. In many cases, these induced earthquakes could cause subsequent noticeable changes in the pattern of seismicity of the area around the dams (Gupta 2002). The magnitude and frequency of such earthquakes being caused by dam impoundment depend on several factors including geological features of the area and physical characteristics of the dam such as the volume of water behind the dam, the dam water level, and probably uncertain factors associ- 
ated with environmental conditions (Talwani 1998, Michas et al 2020). Examinations on the impact of such factors on seismicity patterns have been conducted in Masjed Soleiman, Iran (Tatar et al 2011), Itoiz reservoir, Spain (Durá-Gómez and Talwani 2010), and Koyna dam, India (Gupta 1985). In such field studies, only earthquakes occurring immediately after dam operations have been examined and the long-term effects of these earthquakes which can cause changes in the seismic zone have not been investigated.

Notwithstanding the previous research, more field examinations need to be conducted to compare different dams and their influence of seismicity patterns to help explore the underlying causation mechanisms. To address this gap, the present study further examines five dams in Iran to identify the impact of dam construction on the seismic characteristic of the region. The study area is limited to an area with a radius of $100 \mathrm{~km}$ from the dam seismic parameters in a period of 25 years before and after the dam construction. The rate of seismic changes in any area along with the physical characteristic of any dam, including mean volume and height of the water, were analyzed. Furthermore, significant differences between the depth and distance from the location of the dams and the magnitude and the frequencies of the earthquakes before and after the dam construction have been evaluated using statistical methods. Although geographical conditions play a part in seismicity patterns, for analysis and interpretation purposes, it was assumed that other conditions which may affect the seismicity of the region are constant before and after the operation.

\section{Analysis Methods}

\subsection{Data Collection Approach}

This study focuses on the interventions of dams and only assesses the effects of dam construction on the seismicity pattern of the study areas. Such changes in the seismicity pattern were evaluated using statistical methods. Therefore, other geological and non-geological conditions during the period of the study assumed to be constant.

First and foremost, the criteria for the selection of dams should be clarified. In this study, some criteria were considered for the selection of dams. One of the dam selection criteria was the volume of water behind the dam to be more than 650 million cubic meters. The second criterion was the absence of extensive human activities such as dam construction or mining operations being conducted in the study area in the study period of fifty years. In addition, the long-term operation of dams should be consistent with the duration of the study and also the availability of earthquake data to an acceptable extent.

Based on the criteria mentioned above, five dams including Aras, Dez, Droudzan, Lar and Zayandehroud were selected. Data was collected on these constructed dams to undertake the investigation. Characteristics of each dam including date of operation, average volume and height of water behind the dam, geographic conditions of the 
dam's locations were obtained from the Iranian Water Resources Management Company. Table 1 shows the physical properties including the average height and volume of water behind each dam as well as the reservoir area.

Table 1. Characteristics of the selected dams

\begin{tabular}{|l|c|c|c|c|}
\hline Dam & $\begin{array}{c}\text { Volume } \\
\text { [million cubic meter ] }\end{array}$ & $\begin{array}{c}\text { Height } \\
{[\mathrm{m}]}\end{array}$ & $\begin{array}{c}\text { Reservoir area } \\
{\left[\mathrm{km}^{2}\right]}\end{array}$ & Inaugural \\
\hline Aras & 1254 & 40 & 145 & 1971 \\
Dez & 3465 & 203.5 & 64.9 & 1962 \\
Doroudzan & 960 & 60 & 55 & 1972 \\
Lar & 960 & 107 & 33.5 & 1982 \\
Zayandehroud & 1470 & 100 & 54 & 1970 \\
\hline
\end{tabular}

Furthermore, the data of earthquakes that occurred in the vicinity of the selected dams was gathered from relevant sources, especially the website of Tehran University Geophysics Institute. We also used a uniform catalogue of earthquakes in Iran and neighboring regions (Mirzaei et al 1997). Since the depth of earthquakes recorded in Iran (Jackson 1980), and the data in this catalogue had high uncertainty (Mirzaei et al 1997), the Engdahl catalogue was used, in which given depths are modified for Iran's earthquakes (Engdahl et al 1998).

A time span of 50 years was considered for an in-depth analysis of earthquakes before and after the construction of the dams. Seismic data for twenty-five years before the dam construction is compared with seismic data for twenty-five years after the dam construction. This period spans from 1937 (25 years before the construction of Dez dam) to 2007 (25 years after the construction of the Lar dam).

Prior research reveals that induced earthquakes have occurred at various intervals from dams. Regarding the characteristics of earthquakes in Iran, we considered the maximum possible distance from dams because the average depth of earthquakes in Iran is about 50 kilometers (Maggi et al 2000). The horizontal distance at which these earthquakes are detected is about $50 \mathrm{~km}$ and considering twice this distance $(100 \mathrm{~km})$ can be reassuring in terms of analyzing seismicity effects. Thus, a radius of 100 kilometers from the location of each dam was considered as the study area. In fact, given the mean depth of the earthquake in Iran, which is about 50 kilometers, the maximum distance was chosen. The data was analyzed by Arc GIS 9.3 software using the maximum distance from the dams to the location of earthquakes. After determining and selecting the dams, the study area of each dam was determined as shown in Fig. 1.

Regarding the predicted earthquake magnitudes at the vicinity of the selected dams, it should be noted that the selected dams are constructed at the vicinity of zones with a considerable record of earthquakes. According to the seismic zoning map of peak ground acceleration (PGA) for 475 years return period in Iran, all the dams are located in the zones with PGA level between 0.31 to 0.45 (Zare 2017). Since the earthquake catalogue of Iran included a long period, the quantity and quality of 


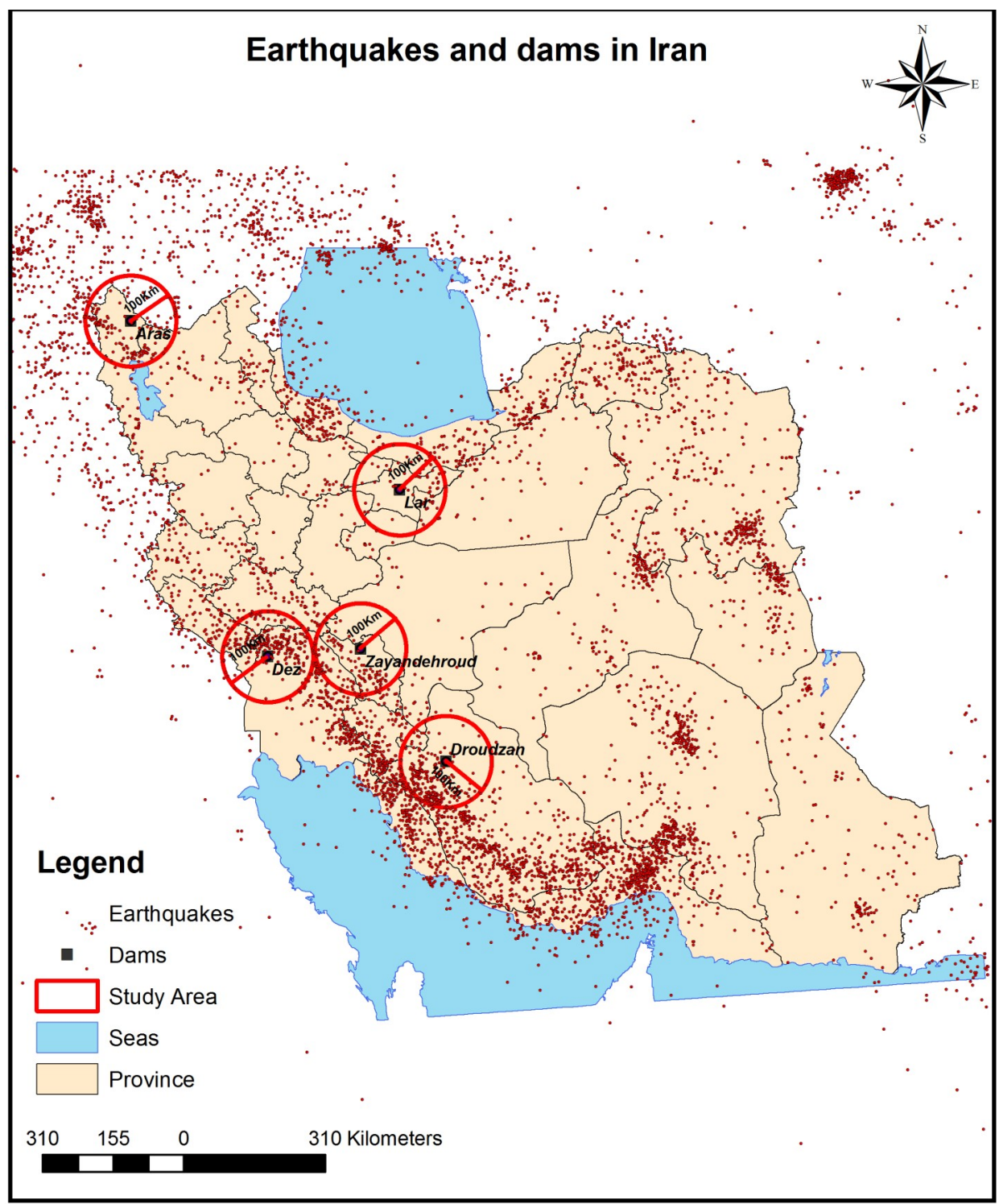

Fig. 1. The distribution of earthquakes in Iran and the location of dams

data is not homogeneous (Neghabat and Liu 1977). So, in several ways, the data were homogenized as follows:

1. Scale conversion. Magnitude scales of surface-wave magnitude (Ms) and moment magnitude $(\mathrm{Mw})$ were converted to body-wave magnitude $(\mathrm{Mb})$ which is the most suitable magnitude scale for our purpose (Gutenberg and Richter 1956). Empirical formula to convert magnitude scales were established by Mirzaei et al (1997). 
2. Removing earthquakes that had $\mathrm{Mb}<4$. In the catalogue, in some cases, the earthquakes that had a magnitude smaller than 4 Richter were not registered. So, we had to remove these earthquakes.

3. Removing foreshocks and aftershocks. Foreshocks and aftershocks occur under the influence of mainshocks in terms of both size and geographical location. Since the aim of this study was checking the mainshocks, therefore by the use of an algorithm, aftershocks are eliminated from this catalogue (Gardner and Knopoff 1974, Molchan and Dmitrieva 1992). In addition, other dependent events are also removed (Öncel and Alptekin 1999). It should be noted that all these steps are done in the Arc GIS 9.3 software. After these stages, we had a set of homogeneous and random data which were suitable for statistical analysis. Overall, 14986 records of earthquakes were collected from relevant sources. After data homogenization and purification, a total of 7698 records were selected in the final dataset for analysis. In fact, 2137 records were related to before the construction of dams and 5561 records after their construction.

\subsection{Data Analysis Approach}

Gutenberg Richter method was used to compare seismicity changes in a radius of 100 kilometers from the dam location. In the respective formula, $N$ is the cumulative frequency of a magnitude $M$ and $L n$ is the natural logarithm. The $\beta$-value can explain the relative density of large and small earthquakes (Lomnitz-Adler and Lomnitz 1979). The $\alpha$-value represents the regional seismicity level (Nanjo and Nagahama 2004). The seismicity parameters of $\alpha$ and $\beta$ were calculated for each region before and after the construction of dams.

$$
\operatorname{Ln}(N)=\alpha-\beta M .
$$

Poisson regression is a part of statistical models termed generalized linear models (García-Rodríguez et al 2008). A generalized linear model consists of continuous dependent variables being linked to independent variables. In this regression, the response variable is numeric and dichotomous (Van Den Eeckhaut et al 2006). The generalized linear model is a flexible generalization of linear regression allowing for response variables with non-normal error distribution. This model allowing the linear model to be related to the response variable and consists of three key elements of (1) an exponential family of probability distributions, (2) A linear predictor $\eta=\chi \times \beta$, and (3) a link function as follows where $\mu$ is the mean of the distribution, $Y$ is the dependent variable and $\times \beta$ represents the linear predictor.

$$
E(Y \mid X)=\mu=g^{-1}(\eta) .
$$

In this study, we followed the Poisson distribution for examining the earthquake data distribution. Significant differences in the number of earthquakes before and after 
the construction of the dam were determined by utilizing this method. Thus, the time of occurrence and the intensity of earthquakes before and after dam construction was considered as the independent variables while the count of earthquakes was defined as a dependent variable.

Independent-Samples T-test was also used in this study as a parameter test that compares the means of independent datasets to determine whether there is statistical evidence that the associated population means are significantly different. Earthquakes caused by impounding of dams are generally shallow (less than $10 \mathrm{~km}$ ) and usually occur near the dam. This characteristic related to earthquakes which rapidly occur following the impoundment of the dams or changes in the reservoir water level (Božović 1974). Thus, a significant difference in the mean depth and distance of the earthquakes that occurred before and after the impounding of dams was evaluated by using Student's test.

\section{Results and Discussions}

\subsection{Analyzing the Impact of Dams on the Seismicity Parameters}

The Gutenberg-Richter method was used to analyze the impact of dams on the seismicity parameters. The seismicity parameters $(\alpha, \beta)$ of the selected dams before and after their construction are given in Table 2 . As shown in this table, seismicity level $(\alpha)$ and relative density of large and small earthquakes $(\beta)$, within a radius of $100 \mathrm{~km}$ of 3 of these dams; Dez, Lar and Zayandehroud have been increased; whereas seismicity parameters of $\alpha$ and $\beta$ have been slightly decreased in Aras and Doroudzan dams.

Table 2. Seismicity parameters before and after dam construction $\alpha$ - regional seismicity level, $\beta$ - relative density of earthquakes, $R^{2}$ - coefficient of determination

\begin{tabular}{|l|c|c|c|c|}
\hline Dam & $\alpha$ & $\beta$ & $R^{2}$ & $R^{2}$ Adjust \\
\hline Aras-Before & -2.13 & 12.06 & 0.93 & 0.92 \\
Aras-After & -1.79 & 10.53 & 0.93 & 0.91 \\
Dez-Before & -0.71 & 4.36 & 0.93 & 0.86 \\
Dez-After & -2.04 & 12.61 & 0.95 & 0.95 \\
Droudzan-Before & -2.85 & 16.05 & 0.96 & 0.95 \\
Droudzan-After & -2.14 & 12.84 & 0.96 & 0.96 \\
Lar-Before & -0.84 & 5.65 & 0.9 & 0.89 \\
Lar-After & -2.007 & 11.02 & 0.98 & 0.98 \\
Zayandehroud-Before & -1.77 & 9.98 & 0.89 & 0.85 \\
Zayandehroud-After & -2.48 & 14.34 & 0.96 & 0.95 \\
\hline
\end{tabular}

According to the results of the Gutenberg-Richter method and physical properties of the dams given in Table 1, in three dams, Dez, Zayandehroud, Lar, when the height of the water behind the dams was over 100 meters, greater differences in seismicity parameters were captured. Furthermore, significant distinctions in the seismicity parameters were observed as the height of water behind these three dams was increased. 
This can be caused by perturbations of the stress and pore pressure due to high water levels in the reservoir (Chander 1999, McGarr et al 2002). It was also found that the average water level in the Lar dam is higher than the Aras dam but the average volume of water stored in the Aras dam is greater than that of the Lar dam. However, the difference in the patterns of seismicity around the Aras dam was not significant.

\subsection{Analyzing the Impact of Dams on the Number of Earthquakes}

The Generalized Linear Model was used to analyze the influence of dams on the number of earthquakes in their vicinity. Table 3 presents the result of significant differences in the number of earthquakes that occurred before and after the construction of dams. The time before and after the dam construction is the independent variable and the number of earthquakes is the dependent variable. There is a significant difference at 0.05 alpha level between the number of occurred earthquakes and the time before and after the construction of Dez, Droudzan, Zayandehroud, and Lar dams. However, there was no significant difference in the Aras dam (P-value $=0.06)$. By using the singular spectrum analysis, Telesca (2012) showed the relationship between seismicity and water level in dam areas. A similar analysis was conducted to examine the relationship between seismicity and the reservoir area, which indicates the same results in terms of the significant impact.

Table 3. Result of the generalized linear model

P-value - calculated probability, $\sigma$ - standard deviation, B - test parameter

\begin{tabular}{|l|c|c|c|c|}
\hline Dam & $B$ & $\sigma$ & P-value & Significance \\
\hline Aras & -0.56 & 0.30 & 0.06 & False \\
Dez & -2.65 & 0.51 & 0.00 & True \\
Droudzan & 0.88 & 0.24 & 0.00 & True \\
Lar & -0.65 & 0.34 & 0.05 & True \\
Zayandehroud & -1.70 & 0.38 & 0.00 & True \\
\hline
\end{tabular}

Fig. 2 consists of two distinct part: The upper part is related to the earthquakes that occurred before the dam construction and the lower part is related to the earthquakes after dam construction. The horizontal line is longitude and the vertical line is latitude. Each earthquake has latitude and longitude irrespective of the location of occurrence. In the upper part, the dots are highlighted concerning the length and latitude of earthquakes that occurred before the dam was built and in the lower part, the dots are marked in different colour, depending on the length and latitude of earthquakes that occurred after the dam construction. In Fig. 2, the number of dots in the analyzed intervals indicates the frequency of earthquakes.

The result of the generalized linear regression is shown in Table 4, where the number of earthquakes was the dependent variable and time and magnitude were independent variables. In two dams, Droudzan and Lar, a significant difference was seen in the 


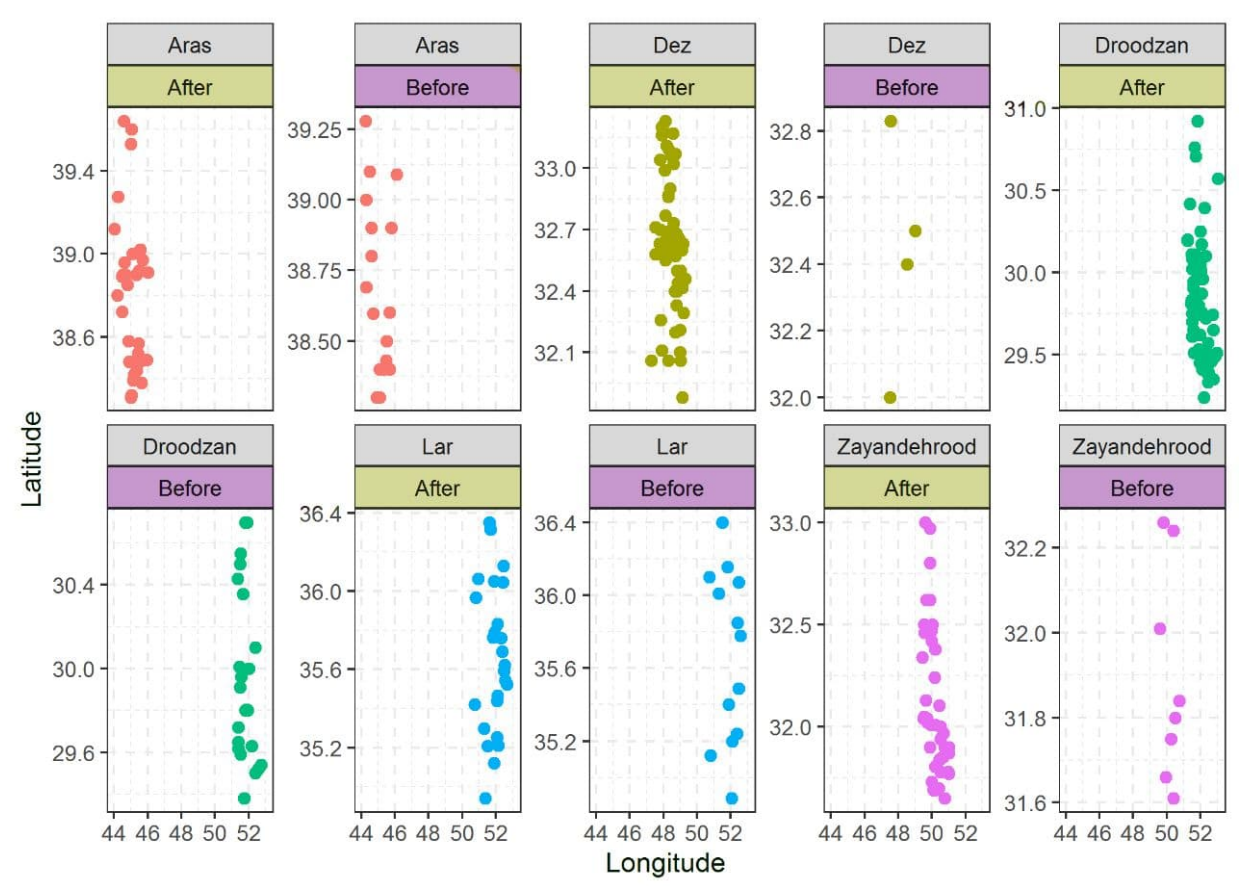

Fig. 2. The count and location of earthquakes before and after the construction of dams

Table 4. Result of the generalized linear model considering the count as the dependent variable, time and magnitude as the independent variable P-value - calculated probability, $\sigma$ - standard deviation, B - test parameter

\begin{tabular}{|l|c|c|c|c|}
\hline Dam & $B$ & $\sigma$ & P-value & Significance \\
\hline Aras & 0.01 & 0.11 & 0.93 & False \\
Dez & -0.09 & 0.089 & 0.3 & False \\
Droudzan & -0.18 & 0.06 & 0.00 & True \\
Lar & -0.38 & 0.07 & 0.00 & True \\
Zayandehroud & -0.04 & 0.10 & 0.66 & False \\
\hline
\end{tabular}

0.05 alpha level. Thus, there is a significant difference between the number of earthquakes with a certain intensity and time before and after the impoundment of dams. In a study, it has been found that the volume of any reservoir affects the local seismic activity (Carder 1945). Many studies have shown that an increase in human activity in a region has enhanced the frequency of earthquakes in subsequent years (Van Eck et al 2006). Thus, it was suggested in order to avoid hazardous caused by the earthquake, a probabilistic seismic hazard analysis to be used. Usually, induced earthquakes are of low intensity, but, in some cases when the magnitude of the earthquakes is more than 6 Richter and like other earthquakes have caused damages (Gupta 2002). Simpson et al have pointed out the fact that these earthquakes not only changed the activity of microearthquakes but, also affected the seismic activity of the destructive earthquakes 
greater than 6 Richter as well (Simpson 1976). Shan et al showed increased pressure on faults in the Wenchuan dam area raises the probability of earthquake occurrence on these faults (Shan et al 2009).

\subsection{Analyzing the Impact of Dams on the Depth of Earthquakes}

Following the Engdahl catalogue (Engdahl et al 1998), the depth reform of Iran's earthquake, significant differences in the mean depth of the earthquakes were examined using a T-test. As seen in Table 5, there are no significant differences between the mean depth of earthquakes, before and after the construction of Lar, Droudzan and Aras dams. In contrast, significant differences in the average depth of earthquakes before and after the construction of the Zayandehroud and Dez dams can be seen. This shows that after construction of these two dams, earthquakes being occurred with magnitudes greater than 4 on the Richter scale are different in the term of earthquake depth with earthquakes occurred before dam construction. These differences may be caused by a series of geological and non-geological conditions that are not included in the study. The results of the statistical test revealed that there is a significant difference between the mean depth of earthquakes before and after the construction of three cases including Dez (P-value $=0.00)$, Lar $(\mathrm{P}$-value $=0.37)$, and Zayandehroud $(\mathrm{P}$-value $=$ $0.03)$; while it is not significant for two dams of Droudzan $(\mathrm{P}$-value $=0.52)$ and Aras $(\mathrm{P}$-value $=0.36)$.

Table 5. The result of the T-test procedure to examine significant differences in the mean depth of earthquakes; P-value - calculated probability, $\alpha$ - significance level

\begin{tabular}{|l|c|c|c|}
\hline Dam & $\alpha$ & P-value & Significant \\
\hline Aras & 0.05 & 0.36 & False \\
Dez & 0.05 & 0.00 & True \\
Droudzan & 0.05 & 0.52 & False \\
Lar & 0.05 & 0.37 & True \\
Zayandehroud & 0.05 & 0.03 & True \\
\hline
\end{tabular}

Fig. 3 shows the depth and magnitude of earthquakes that occurred after and before the dam construction within a $100 \mathrm{~km}$ radius of the dam. The horizontal line is the magnitude of earthquakes and the vertical lines represent the depth of earthquakes. The earthquakes that occurred before the dam construction are marked in coloured dots and earthquakes that occurred after the dam construction are marked in different colour dots. We used the T-test to compare the mean distance of earthquakes from the location of dams before and after their construction.

As illustrated in Table 6, there is no significant difference between the mean distance of earthquakes from the dam site before and after construction. Since, for the homogenization of earthquake data, we were forced to remove earthquakes smaller than magnitude 4, and T-test results were not significant, which seems to be logical. 


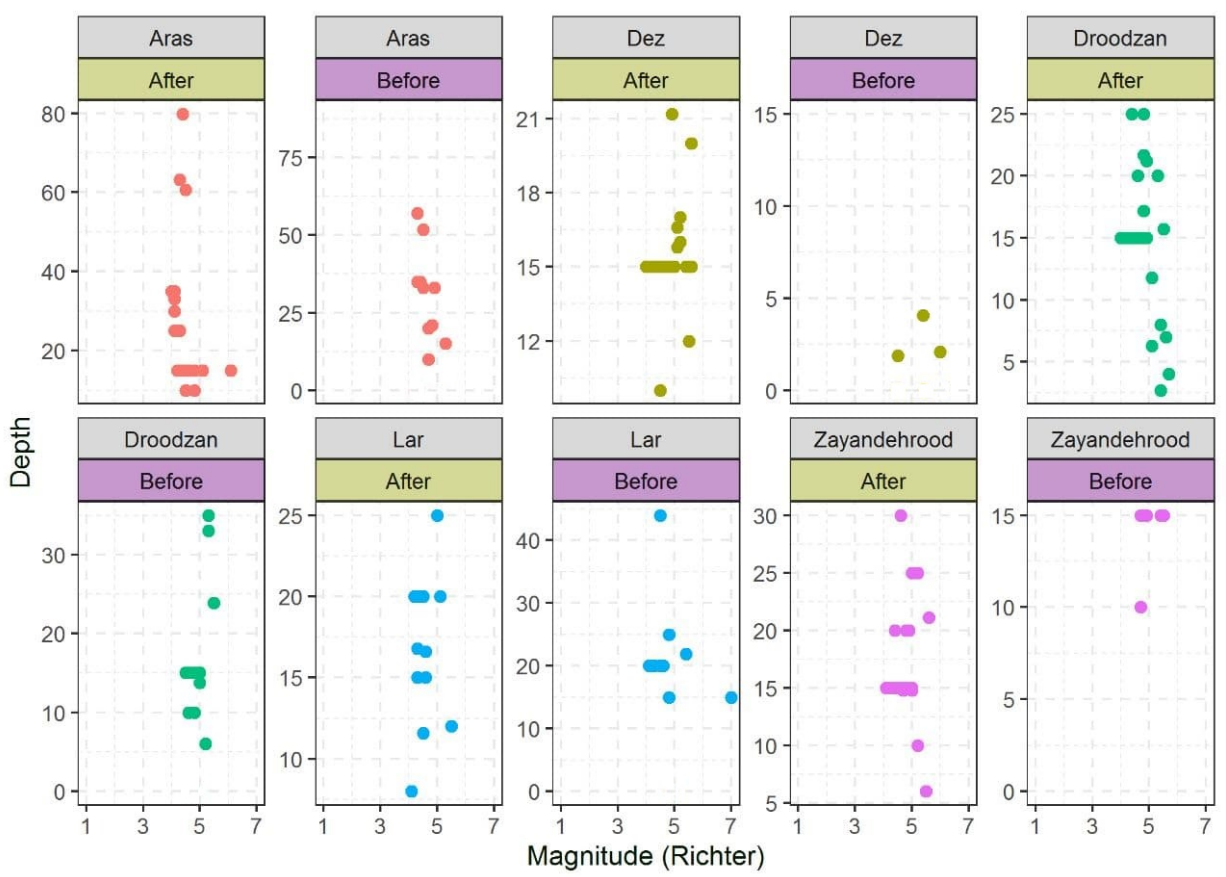

Fig. 3. Depth and magnitude of earthquakes before and after the construction of dams

Table 6. The results of the T-test procedure to examine significant differences in the mean distance of earthquakes; P-value - calculated probability, $\alpha$ - significance level

\begin{tabular}{|l|c|c|c|}
\hline Dam & $\alpha$ & P-value & Significant \\
\hline Aras & 0.05 & 0.12 & False \\
Dez & 0.05 & 0.87 & False \\
Droudzan & 0.05 & 0.52 & False \\
Lar & 0.05 & 0.11 & False \\
Zayandehroud & 0.05 & 0.773 & False \\
\hline
\end{tabular}

In Fig. 4, the vertical line is the distance between the site of dams and earthquakes. The horizontal line is the intensity of earthquakes. The horizontal view is divided into two parts, before and after the construction of the five dams studied. The upper parts show earthquakes that occurred before the dam was built, and marked in different colour. The lower part shows the earthquakes that occurred after the dam construction and are shown differently. Indeed, distance earthquakes with the determined magnitude before and after the construction of dams has been shown in Fig. 4. The earthquakes are scattered from less than $20 \mathrm{~km}$ to $100 \mathrm{~km}$ from the dam site. The same distribution is observed after the construction of dams and is not significantly different from before the construction of dams.

As a reference point, there is no significant impact on (1) seismicity parameters, (2) the number of earthquakes, (3) the depth of earthquakes, and (4) the distance of 


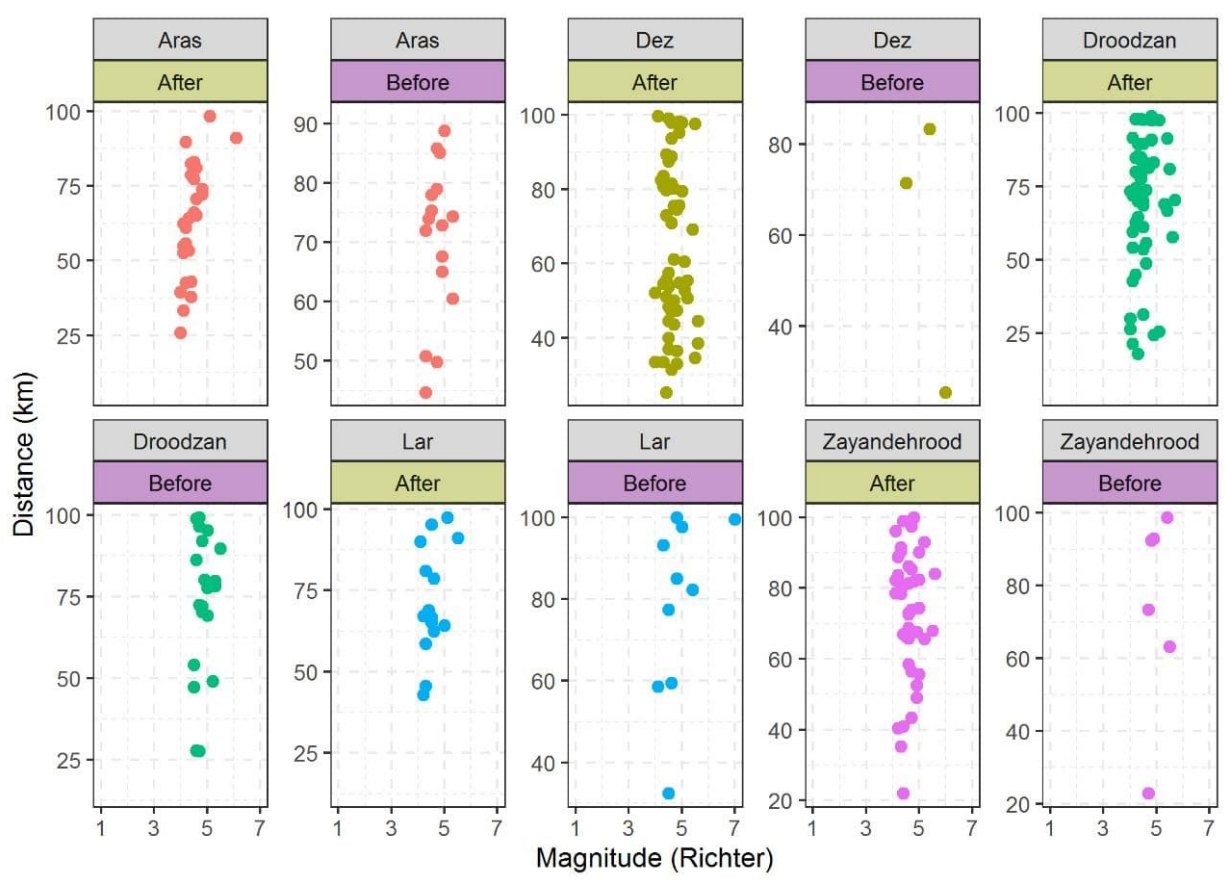

Fig. 4. Distance earthquakes with the determined magnitude before and after the construction of dams

earthquakes to dams before and after the construction of the Aras dam; while the impact of other four dams on these four earthquake-related criteria is not the same. The analysis of earthquakes in the vicinity of the dams Dez, Lar, and Zayandehroud revealed the impact of dams on the seismicity parameters, frequency, and depth of earthquakes; while the analysis of records with regard to the Droudzan dam showed significant impact just on the frequency of the earthquakes (Table 7).

Table 7. An overview of the impact of dams on earthquake characteristics

\begin{tabular}{|l|c|c|c|c|}
\hline \multirow{2}{*}{ Dam } & \multicolumn{4}{|c|}{ Impacts } \\
\cline { 2 - 5 } & Seismicity parameters & Frequency & Depth & Distance \\
\hline Aras & $\vee$ & $\vee$ & $\vee$ & \\
Dez & $\vee$ & $\vee$ & & \\
Droudzan & & $\vee$ & $\vee$ & \\
Lar & $\vee$ & $\vee$ & $\vee$ & \\
Zayandehroud & $\vee$ & & \\
\hline
\end{tabular}

This study assumed that geological conditions are constant while it is worth exploring their possible impacts on the seismicity behavior of dams. For example, the distance to fault zones is one of the important geological conditions to be characterized in the selected set of dams. Three selected dams (Dez, Zayandehroud, and Doroudzan) are almost close to the active Zagros fold-and-thrust belt while the other 
two dams (Lar and Aras) are located far from this zone. Future studies are encouraged to further study the influence of geological conditions by conducting experimental research. Analytical methods such as fuzzy analytical hierarchy process (Ershadi et al 2016) can be used to prioritize and select the best location for construction of the dam so that minimum impact is left on the surrounding scismisity area. Another potential direction for future research would be to analyze the dynamic relationships between variables that may impact the scismisity patterns in the vicinity of dams using system dynamics method (Goodarzi et al 2016).

\section{Conclusion}

Statistical examination of the impact of dams on seismicity patterns can be helpful in emergency response, preventing and reducing environmental impacts. In this study, we tried with the help of statistical methods, to determined seismicity change in the area where dams are constructed. We identified the characteristics of the induced earthquakes caused by the dams, such as the depth, magnitude and distance of their occurrence from the location where the dam was constructed. And we tried to investigate changes in these characters in earthquakes that occurred before and after dam construction. We also considered the physical properties of the dams such as the average volume of water stored and the average height of water behind the dam.

Results of the present study suggested that the operation of dams is associated with changes in the pattern of seismicity in the areas. According to the result of the Gutenberg Richter, a valid method for determining the level of seismicity zones, show that in some dams such as Dez, Zayandehroud and Lar causing an increase of seismicity and in other dams, Aras and Droudzan resulting in a decrease of seismicity. It also seems that the variable of water level behind the dam is more effective than the mean volume of water in the number of seismicity changes. The results of this study will help us in the future have an effective risk assessment for energy project such as dam construction.

\section{Acknowledgement}

The authors would like to acknowledge the support of Tehran University of Medical Sciences for supporting this research.

\section{References}

Adnan A., Harith N. (2017) Estimation of peak ground acceleration of Ranau based on recent earthquake databases, Malaysian Journal Geosciences, 1, 6-9.

Božović A. (1974) Review and appraisal of case histories related to seismic effects of reservoir impounding, Engineering Geology, 8, 9-27.

Carder D. S. (1945) Seismic investigations in the Boulder Dam area, 1940-1944, and the influence of reservoir loading on local earthquake activity, Bulletin of the Seismological Society of America, 35, $175-192$. 
Castle R. O., Clark M. M., Grantz A., Savage J. C. (1980) Tectonic state: its significance and characterization in the assessment of seismic effects associated with reservoir impounding, Engineering Geology, 15, 53-99.

Chander R. (1999) Can dams and reservoirs cause earthquakes? Resonance, 4, 4-13.

Durá-Gómez I., Talwani P. (2010) Reservoir-induced seismicity associated with the Itoiz Reservoir, Spain: a case study, Geophysical Journal International, 181, 343-356.

Ellsworth W. L. (2013) Injection-induced earthquakes, Science, 341 (6142): 1225942.

Engdahl E. R., Van Der Hilst R., Buland R. (1998) Global teleseismic earthquake relocation with improved travel times and procedures for depth determination, Bulletin of the Seismological Society of America, 88, 722-743.

Ershadi M., Arsanjani M. A., Nayebvali R., Akrami S. (2016) Prioritizing PMO functions in organizations: A group fuzzy decision making approach, Indian Journal of Science and Technology, 9, 13.

Foltz R. C. (2002) Iran's water crisis: cultural, political, and ethical dimensions, Journal of Agricultural and Environmental Ethics, 15, 357-380.

Frohlich C., Potter E., Hayward C., Stump B. (2010) Dallas-Fort Worth earthquakes coincident with activity associated with natural gas production, The Leading Edge, 29, 270-275.

García-Rodríguez M. J., Malpica J., Benito B., Díaz M. (2008) Susceptibility assessment of earthquake-triggered landslides in El Salvador using logistic regression, Geomorphology, 95, 172-191.

Gardner J., Knopoff L. (1974) Is the sequence of earthquakes in southern California, with aftershocks removed, Poissonian. Bull. Seismol. Soc. Am, 64, 1363-1367.

Goodarzi F., Ershadi M., Arsanjani M. A., Firouzshahi M. (2016) System dynamics modelling of air pollution in megacities: An investigation in megacity of Tehran, Applied Environmental and Biological Sciences, 6, 7-13.

Gupta H. K. (1985) The present status of reservoir induced seismicity investigations with special emphasis on Koyna earthquakes, Tectonophysics, 118, 257-279.

Gupta H. K. (2002) A review of recent studies of triggered earthquakes by artificial water reservoirs with special emphasis on earthquakes in Koyna, India, Earth-Science Reviews, 58, 279-310.

Gupta H. K., Rastogi B., Narain H. (1972) Common features of the reservoir-associated seismic activities, Bulletin of the Seismological Society of America, 62, 481-492.

Gutenberg B., Richter C. F. (1956) Magnitude and energy of earthquakes, Annals of Geophysics, 9 , $1-15$.

Ibenbrahim A., Ni J., Salyards S., Ali I. M. (1989) Induced seismicity of the Tarbela reservoir, Pakistan, Seismological Research Letters, 60, 185-197.

Jackson J. (1980) Errors in focal depth determination and the depth of seismicity in Iran and Turkey, Geophysical Journal International, 61, 285-301.

Kusznir N., Ashwin D., Bradley A. (1980) Mining induced seismicity in the North Staffordshire coalfield, England, International Journal of Rock Mechanics and Mining Sciences \& Geomechanics Abstracts, 17 (1), 45-55.

Lomnitz-Adler J., Lomnitz C. (1979) A modified form of the Gutenberg-Richter magnitude-frequency relation, Bull. Seism. Soc. Am., 69, 1209-1214.

Maggi A., Jackson J., Priestley K., Baker C. (2000) A re-assessment of focal depth distributions in southern Iran, the Tien Shan and northern India: Do earthquakes really occur in the continental mantle? Geophysical Journal International, 143, 629-661.

Manouchehri G., Mahmoodian S. (2002) Environmental Impacts of dams constructed in Iran, International Journal of Water Resources Development, 18, 179-182. 
McGarr A., Simpson D., Seeber L. (2002) Case histories of induced and triggered seismicity, International Geophysics Series, 81, 647-664.

Michas G., Pavlou K., Vallianatos F., Drakatos G. (2020) Correlation Between Seismicity and Water Level Fluctuations in the Polyphyto Dam, North Greece, Pure and Applied Geophysics, 1-20.

Mirzaei N., Gao M.-T., Chen Y.-T., Wang J. (1997) A uniform catalog of earthquakes for seismic hazard assessment in Iran, Acta Seismologica Sinica, 10, 713-726.

Molchan G., Dmitrieva O. (1992) Aftershock identification: methods and new approaches, Geophysical Journal International, 109, 501-516.

Nanjo K., Nagahama H. (2004) Fractal properties of spatial distributions of aftershocks and active faults, Chaos, Solitons \& Fractals, 19, 387-397.

Neghabat F., Liu S. (1977) Earthquake regionalization of Iran, Proceedings of the 7th world conference earthquake engineering, Delhi, 536-551.

Ohtake M. (1974) Seismic activity induced by water injection at Matsushiro, Japan, J. Phys. Earth, 22, 163-176.

Öncel A., Alptekin Ö. (1999) Effect of aftershocks on earthquake hazard estimation: an example from the North Anatolian fault zone, Natural Hazards, 19, 1-11.

Pavan Kumar J., Ramana D., Chadha R., Singh C., Shekar M. (2012) The relation between seismicity and water level changes in the Koyna-Warna region, India, Natural Hazards and Earth System Science, 12, 813-817.

Rothé J. P. (2013) Summary: Geophysics Report, Man-Made Lakes: Their Problems and Environmental Effects, American Geophysical Union, 441-454.

Shan B., Xiong X., Zheng Y., Diao F. (2009) Stress changes on major faults caused by M w 7.9 Wenchuan earthquake, May 12, 2008, Science in China Series D: Earth Sciences, 52, 593-601.

Simpson D. W. (1976) Seismicity changes associated with reservoir loading, Engineering Geology, 10, $123-150$.

Simpson D., Negmatullaev S. K. (1981) Induced seismicity at Nurek reservoir, Tadjikistan, USSR, Bulletin of the Seismological Society of America, 71, 1561-1586.

Talwani P. (1998) On the nature of reservoir-induced seismicity, ure and applied Geophysics, 150 (3), 473-492.

Tatar M., Ebrahimi M. R., Yamini Fard F. (2011) Induced Seismicity in Masjed Soleyman Reservoir (Southwest of Iran), Journal of Geoscience, 20 (80), 95-102.

Telesca L., Matcharasvili T., Chelidze T., Zhukova N. (2012) Relationship between seismicity and water level in the Enguri high dam area (Georgia) using the singular spectrum analysis, Natural Hazards and Earth System Sciences, 12, 2479-2485.

Van Den Eeckhaut M., Vanwalleghem T., Poesen J., Govers G., Verstraeten G., Vandekerckhove L. (2006) Prediction of landslide susceptibility using rare events logistic regression: a case-study in the Flemish Ardennes (Belgium), Geomorphology, 76, 392-410.

Van Eck T., Goutbeek F., Haak H., Dost B. (2006) Seismic hazard due to small-magnitude, shallow-source, induced earthquakes in The Netherlands, Engineering Geology, 87, 105-121.

Wald S. H. L. (2015) Earthquakes with 1,000 or More Deaths 1900-2014 [online]. http://earthquake.usgs.gov/earthquakes/world/world_deaths.php [Accessed Access Date 2015].

Zare M. (2017) Seismic hazard zoning in Iran: a state-of-the-art on the studies during four decades, Journal of Seismology and Earthquake Engineering, 19 (2), 71-101. 